\title{
Behavior of Nitrite Oxidizers in the Nitrification/Denitrification Process for the Treatment of Simulated Coke-Oven Wastewater
}

\author{
Yuki Takasaki*, Hiroyasu Satoh*, Motoharu Onuki**, Takashi Mino*, Kimio \\ Ito***, and Osamu Miki*** \\ *: Institute of Environmental Studies, Univ. of Tokyo \\ **: Integrated Research System for Sustainability Science, Univ. of Tokyo \\ ***: Advanced Technology Research Laboratories, Nippon Steel Corporation)
}

\begin{abstract}
The behavior of nitrite oxidizers in the nitrification/denitrification process for the treatment of coak-oven wastewater was studied by using molecular methods. An activated sludge process was operated with simulated coak-oven wastewater. In the existence of thiosulfate, partial nitrification was observed, while in its absence, full nitrification was observed. In the activated sludge treating simulated coak-oven wastewater, only Nitrobacter species were found as the nitrite oxidizers by using PCR and FISH targeted at different nitrite oxidizers. The QP-PCR (quenching primer PCR) method was applied for the quantitative monitoring of Nitrobacter species. The QP-PCR method demonstrated that Nitrobacter species increased when thiosulfate was absent. Nitrobacter species was found to have been the major nitrite oxidizing species at least in one of the operational periods with full nitrification. On the other hand, in another period with full nitrification, their absolute amount was too small to explain nitrite oxidation.
\end{abstract}

Key words coak oven wastewater; partial nitrification; Nitrobacter; quenching primer PCR.

\section{INTRODUCTION}

The wastewater from coke-ovens for steel industries contains high concentrations of toxic compounds such as cyanide and phenol as well as ammonia. If the treated wastewater is to be discharged to enclosed water bodies, nitrogen removal is needed in addition to the removal of toxic compounds. Yet, as nitrifiers are in general known to be sensitive to toxic compounds, the application of biological methods such as nitrification/denitrification has been thought to be difficult. Yet, there are cases where biological nitrification has been applied successfully.

The authors examined the applicability of the nitrification/denitrification process for the treatment of coak-oven wastewater diluted with sea water. In the preliminary 
experiment, the authors observed the accumulation of nitrite instead of nitrate in the nitrification step. In an attempt to clarify the cause of partial nitriifcation, the authors operated a test plant using simulated coak-oven wastewater prepared with chemical reagents for a period of about one year. The nitrifiers population was monitored by molecular methods including fluorescence in situ hybridization (FISH), PCR-DGGE, and real time PCR.

\section{MATERIALS AND METHODS}

\section{Operation of the reactor}

A bench-scale continuous activated sludge process was operated with simulated coak-oven from October 2002 to September 2003. The effective reactor consisted of $45 \mathrm{~L}$ of anoxic tank and $135 \mathrm{~L}$ of aerobic tank, and a sedimentation tank. Influent was 60L/day. pH was 8.0-8.5 in the anoxic tank, and 7.0-7.5 in the aerobic tank. The water temperature was $25^{\circ} \mathrm{C}-30^{\circ} \mathrm{C}$. The sludge retention time (SRT) was maintained at 50days until March 2003, and at 30days after April 2003. The reactor set-up is illlusterated in Figure 1. The composition of the simulated coak oven wastewater is shown in Tabls

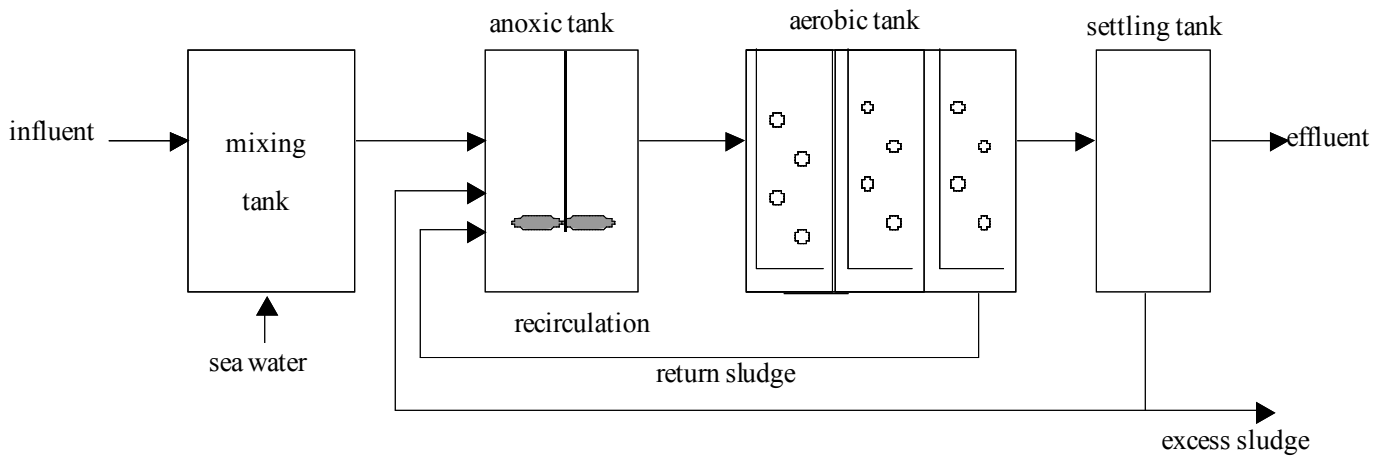

Figure 1 Bench-scale continuous activated sludge process

Table 1 Influent Composition to the Bench-Scale Simulated Activated Sludge Process

\begin{tabular}{|c|c|c|c|c|c|c|c|}
\hline RUN & RUN1 & RUN2 & RUN3 & RUN4 & RUN5 & RUN6 & $\begin{array}{l}\text { RUN } \\
7\end{array}$ \\
\hline DATE & $\begin{array}{l}2002 \\
10 / 18-11 / 12\end{array}$ & $\begin{array}{l}11 / 12- \\
12 / 9\end{array}$ & $\begin{array}{l}2003 \\
12 / 9-1 / \\
17\end{array}$ & $\begin{array}{l}1 / 17-3 / \\
13\end{array}$ & $\begin{array}{l}3 / 13-4 / \\
17\end{array}$ & $\begin{array}{l}4 / 17-7 / \\
4\end{array}$ & $\begin{array}{l}7 / 4-9 / \\
26 \\
\end{array}$ \\
\hline $\begin{array}{l}\text { Real Coak Oven } \\
\text { Wastewater } \\
\text { Phenol } \\
\mathrm{SCN}- \\
\mathrm{S}_{2} \mathrm{O}_{3} \text { - } \\
\mathrm{Sea} \text { Water } \\
\mathrm{Na}_{2} \mathrm{HPO}_{4}-12 \mathrm{H}_{2} \mathrm{O}\end{array}$ & $\begin{array}{l}5(\%) \\
600(\mathrm{mg} / \mathrm{L}) \\
100(\mathrm{mg} / \mathrm{L}) \\
300(\mathrm{mg} / \mathrm{L}) \\
60(\%) \\
51(\mathrm{mg} / \mathrm{L})\end{array}$ & $\begin{array}{l}- \\
100 \\
300 \\
60 \\
51\end{array}$ & $\begin{array}{l}5 \\
600 \\
100 \\
300 \\
60 \\
51\end{array}$ & $\begin{array}{l}- \\
600 \\
100 \\
300 \\
60 \\
51\end{array}$ & $\begin{array}{l}- \\
600 \\
- \\
- \\
60 \\
51\end{array}$ & $\begin{array}{l}- \\
600 \\
- \\
300 \\
60 \\
51\end{array}$ & $\begin{array}{l}- \\
600 \\
- \\
- \\
60 \\
51\end{array}$ \\
\hline
\end{tabular}




\section{Chemical Analyses}

Following parameters were monitored. $\mathrm{pH}, \mathrm{SS}, \mathrm{TN}, \mathrm{DTN}, \mathrm{NH} 4-\mathrm{N}, \mathrm{NO} 2-\mathrm{N}, \mathrm{NO} 3-\mathrm{N}$, $\operatorname{COD}(\mathrm{Cr})$, D-COD $(\mathrm{Cr})$, D-phenol, D-SCN, D-S2O3, D-SO4, and alkalinity, MLSS, MLVSS, DO, ORP, water temperature.

\section{Microbial analyses}

Activated sludge samples were added with ethanol at a final concentration of $10 \%$, then transported to the laboratory of UT at 4oCstored. Then, each of the samples were divided into two. One of them was for DNA extraction and was washed with TE buffer at $\mathrm{pH} 8.0$, and stored at $-20 \mathrm{oC}$. Another was for FISH analysis and was stored at $-80 \mathrm{oC}$.

The extraction of DNA was performed with Fast DNA SPIN Kit for Soil (Qbuiogene, USA) according to the instruction by the manufacturer.

In the preliminary step to nawwor down the species of NOB, the primer set FGPS872f, CTAAAACTCAAAGGAATTGA and FGPS1269r , TTTTTTGAGATTTGCTAG (Degrange and Bardin, 1995) was employed for the detection of Nitrobacter species, and the primer set NSR1113f CCTGCTTTCAGTTGCTACCG and NSR1264r GTTTGCAGCGCTTTGTACCG

Dionishi et al., 2002) were employed for the detection of Nitrospira species. In addition, FISH analyses targeted at different nitrite oxidizing bacteria were performed. NIT3, CCTGTGCTCCATGCTCCG (Wagner et al., 1995), Ntspa662, GGAATTCCGCGCTCCTCT Ntspn692, TTCCCAATATCAACGCATTT, Ntspn994, CAAGGCGGTCCCAAGCAA， Ntcoc84， TCGCCAGCCACCTTTCCG， Ntcoc206, CGGTGCGAGCTTGCAAGC (Juretschko et al. 2000).

Quanching Primer method (Kurata et al., 2001), one of quantitative PCR methods, was peformed with the primser set FGPS872f and FGPS1269r, where FGPS872 $\mathrm{f}$ was added with a fluorescent dye Bodipy at its 5' end. ABI7000 real time PCR thermal cycler was employed.

\section{RESULTS AND DISCUSSION}

The behavior of nitrification is as shown in Figure 2. Only in Run 5 and 7, full nitrification was observed. It was only in these two runs that were not added with thiosulfate. Thiosulfate must have affected the activities of nitrite oxidizing bacteria. 


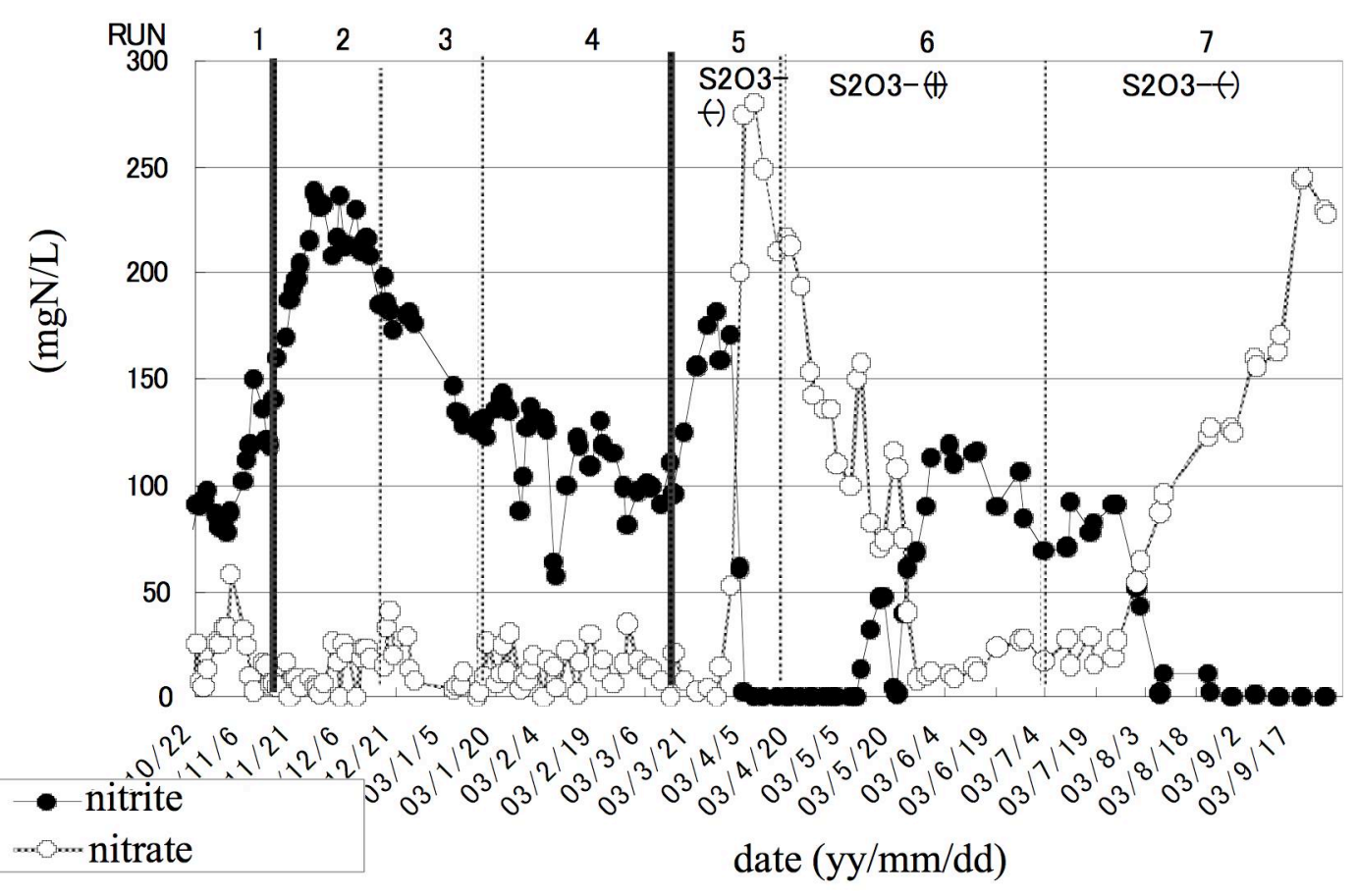

Figure 2 Behavior of nitrate and nitrite at the end of the aerobic tank.

\section{Behavior of Nitrobacter species}

The analysis of nitrite oxidizing bacteria was performed with PCR and FISH. By both of PCR and FISH analyses, only Nitrobacter species were detected.

The PCR result with FGPS primer set is shown in Figure 3. The band intensitis were quantified, and were plotted in Figure 4.

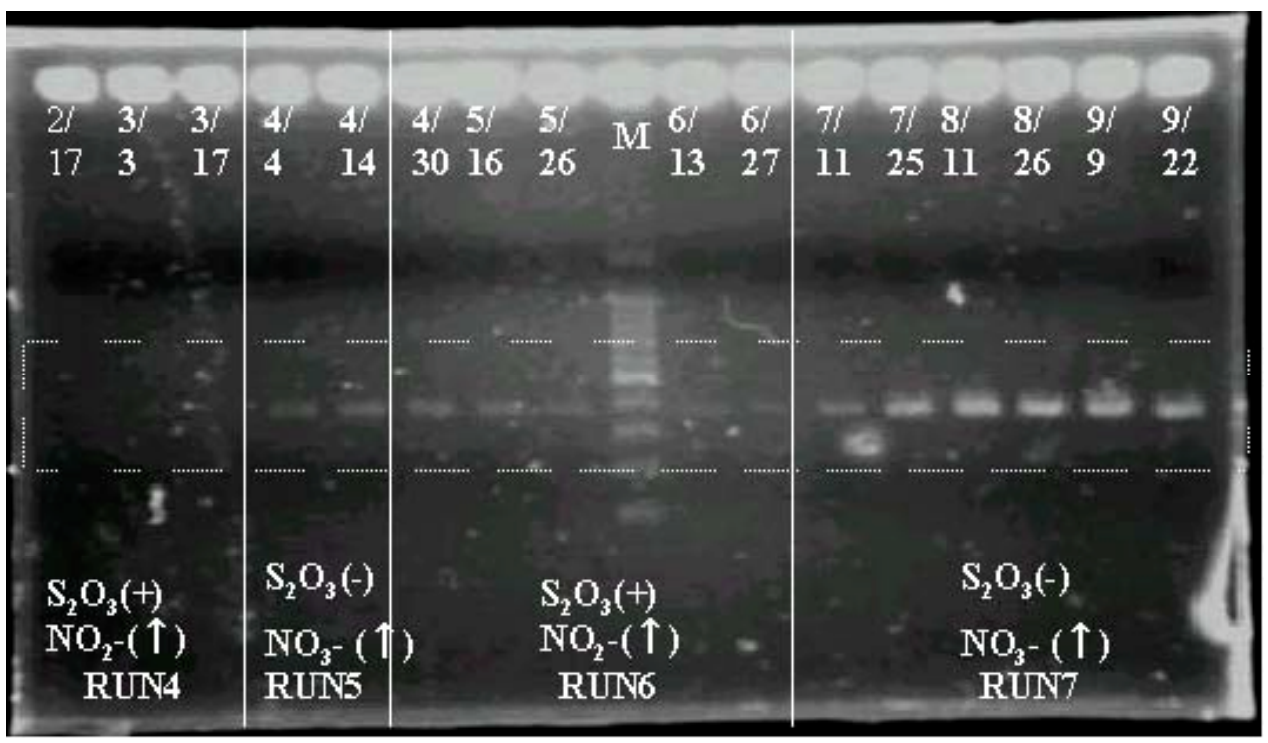

Figure 3. Nitrobacter species detected by PCR 


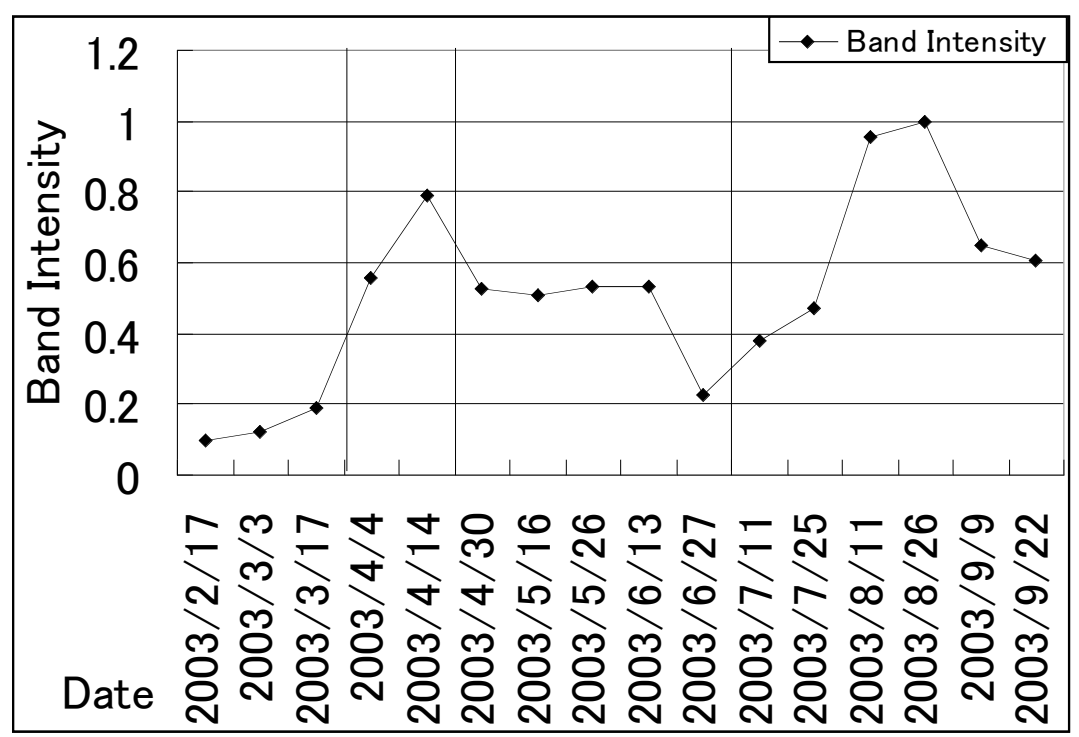

Figure 4. Band intensities for Nitrobacter species

While in Figure 4, the band intensities were high only in Runs 5 and 7, and their band intensities were quite similar, PCR method in general is known not as quantitative. In order to more accurately determine the behavior of nitrifiers, a quantitqative PCR method (Quanching Primer-PCR) for the determination of Nitrobacter species was developed by using the same primer set in combination with a fluorescent dye Bodipy. The method is so-called Quanching Primer PCR (QP-PCR) method developed by Kurata et al. (2001).

Different conditions for the implementation of QP-PCR was applied, and the condition was optimized. In general, the higher concentration of primers can lead to the formation of primer dimers. Also, the cost of the chemicals should be minimized if the same quantitativeness can be achieved. The results with different conditions tested are shown in Figure 5. As can be found in Figure 5, the tested three conditions gave similar accuracies. The authors decided to use Takara Taq polymerase (Takara, Japan) with the primer concentrations of 0.2 micro-M. The denaturing curve shown in Figure 6 showed that target sequences were multiplied without the formation of non-target sequences. 

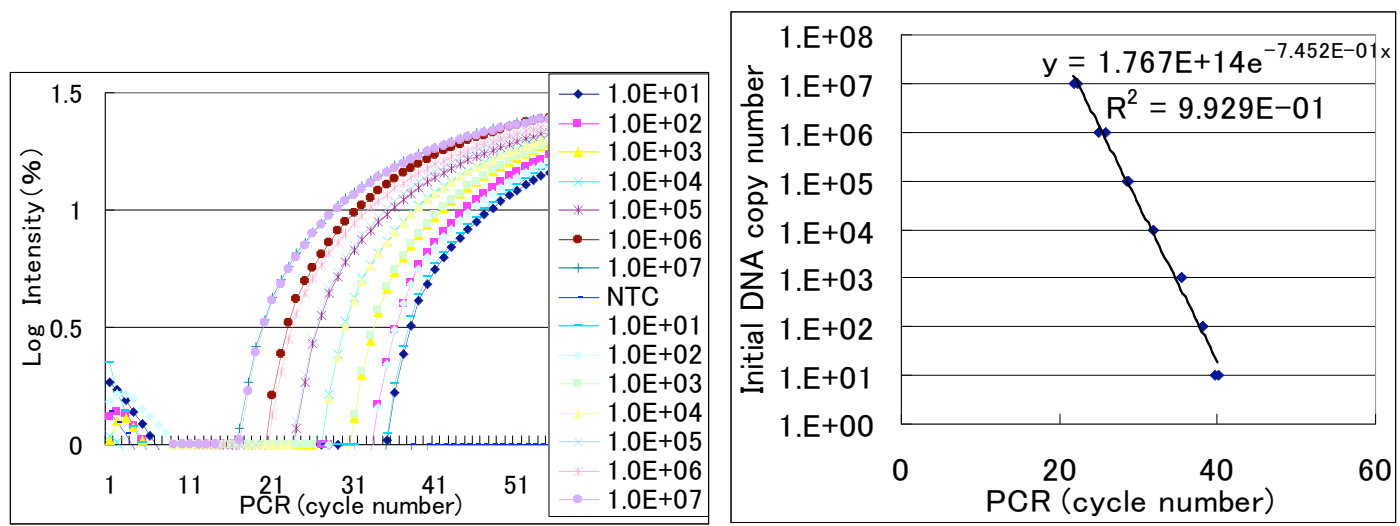

(a) AmplitaqGold with primer $0.2 \mathrm{microM}$
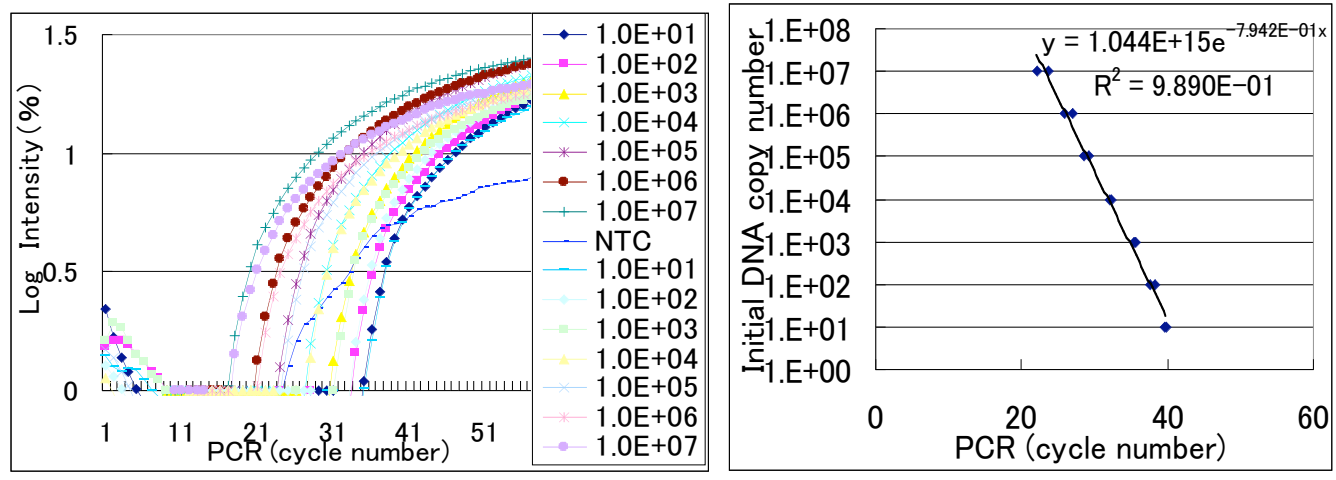

(b) AmplitaqGold with primer $0.4 \mathrm{microM}$
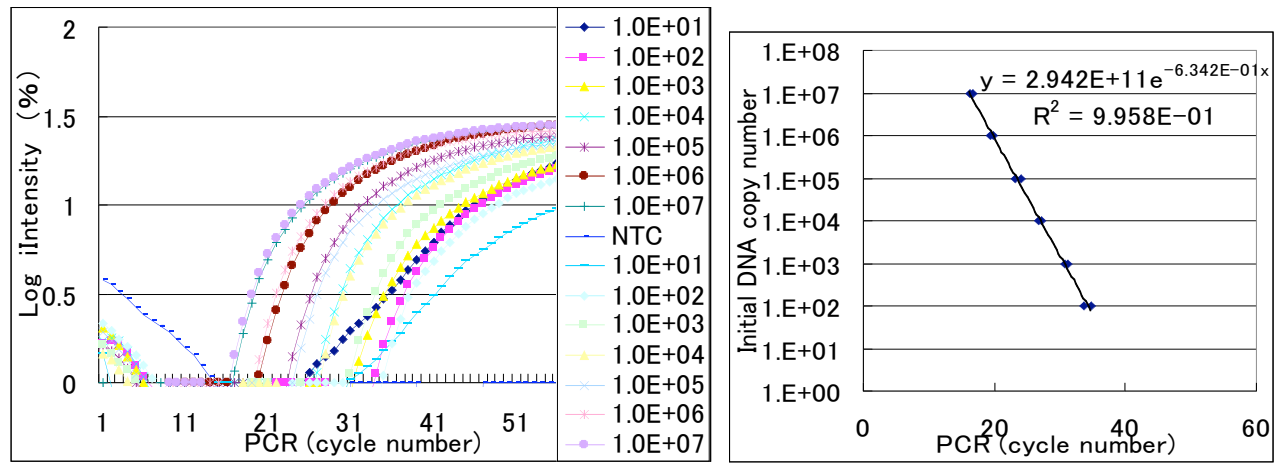

(c) Takara Taq Polymerase with primer 0.2 microM

Figure 5 Amplifications of target sequences under different conditions by QP PCR with FGPS primer set 


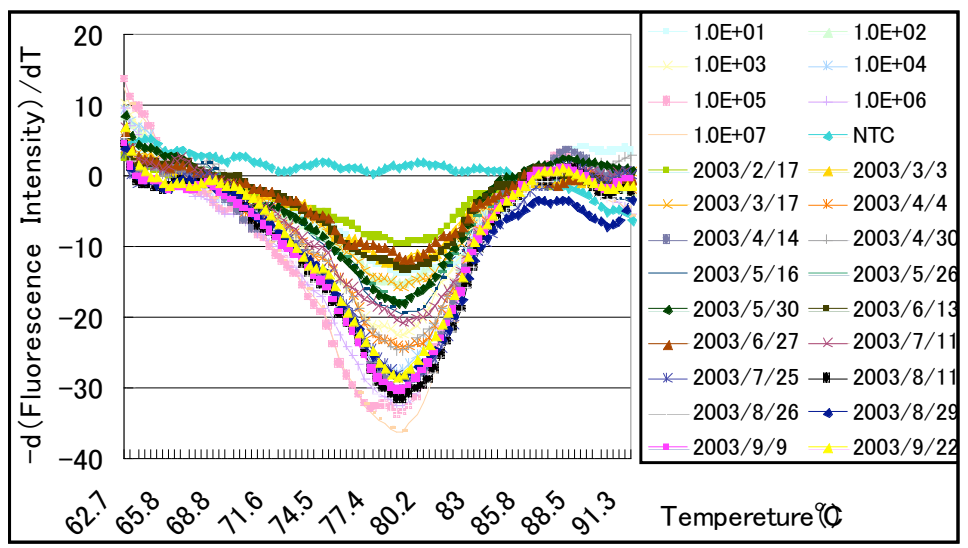

Figure 6 Denaturing curve of PCR products by QP-PCR with FGPS primer set

The QP-PCR method was applied to the activated sludge sample for quantitative monitoring of Nitrobacter species. The result is shown in Figure 7.

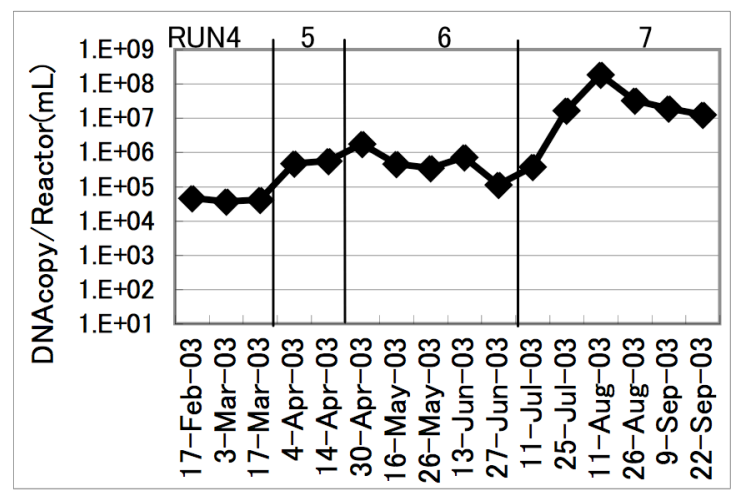

Figure 7 Quantity of Nitrobacter speices monitored by QP-PCR.

Both in Runs 5 and 7, when thiosulfate was not added in the influent, increase of Nitrobacter species was clearly detected. On the other hand, Nitrobacter decreased during Run 6 when thiosulfate was added. These trends can also be seen in Figure 4. Yet, the amounts of Nitrobacter species in Run 5 and Run 7 differed in two orderes. In Runs 5 and 7, the nitrite oxidation activities were in the same order. Here, a quastion arises why similar nitrite oxidation was observed with two-order different quantities of Nitrbacter species provided if only Nitrobacter species were the sole nitrite oxidizers. While in Run 7 Nitrobacter species was the main nitrite oxidizer, it is not clear if Nitrobacter species was the main nitrite oxidizer in Run 5.

\section{CONCLUSIONS}

An activated sludge process was operated with simulated coak-oven wastewater. In the existence of thiosulfate, partial nitrification was observed, while in its absence, full 
nitrification was observed. In the activated sludge treating simulated coak-oven wastewater, only Nitrobacter species was found as the nitrite oxidizer by using PCR and FISH targeted at different nitrite oxidizers. The QP-PCR method was applied for the quantitative monitoring of Nitrobacter species. The QP-PCR method demonstrated that Nitrobacter species increased during Runs 5 and 7 when thiosulfate was absent. Nitrobacter species was found to have been the major nitrite oxidizing species at least in Run 7. On the other hand, in Run 5, while Nitrobacter species increased, their absolute amount was two orders lower than in Run 7. It is not still clear who took the role of full nitrification in Run 5.

\section{REFERENCES}

Amann, R.I., Ludwig, W. and Schleifer, K. H. 1995. Phylogenetic identification and in situ detection of individual microbial cells without cultivation, Microbial Reviews. 59:143-169.

Degrange, V., and Bardin, R. 1995. Detection and Counting of Nitrobacter Populations in Soil by PCR. Appl. Envir. Microbiol. 61:2093-2098

Dionisi, H. M., Layton, A. C., Harms, G., Gregory, I. R., Robinson, K. G., and Sayler, G. S. 2002. Quantification of Nitrosomonas oligotropha-like ammonia-oxidizing bacteria and Nitrospira spp. from full-scale wastewater treatment plants by competitive PCR Appl. Environ. Microbiol. 68:245-253

Juretschko S. 2000. Mikrobielle Populationsstruktur und -dynamik in einer nitrifizierenden/denitrifizierenden Belebtschlammanlage. Doctoral thesis (Technische Universität München)

Kurata, S., Kanagawa, T., Yamada, K., Torimura, M., Yokomaru, T., Kamagata, Y., and Kurane, R. 2001 Fluorescent Quenching-based Quantitative Detection of Specific DNA/RNA BODIPY® FL-labeled Probe or Primer, Nucleic Acids Research, 29: e34.

Wagner, M., G. Rath, R. Amann, H.-P. Koops, and K.-H. Schleifer ; 1995 . In situ identification of ammonia-oxidizing bacteria Syst. Appl. Microbiol. 18:251-264 